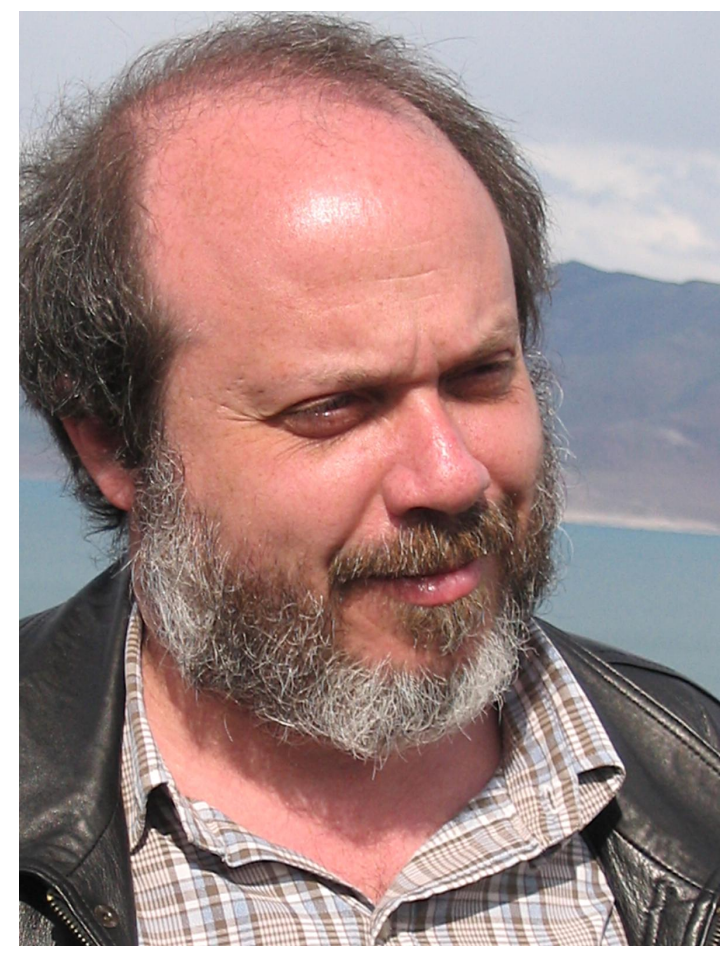

\title{
Alexander A. Golovin (1962-2008)
}

This issue of the journal is devoted to the memory of Alexander (Sasha) Golovin, who passed away on September 10, 2008 after a year-long battle with cancer.

After receiving his undergraduate and graduate degrees from the Moscow Institute of Physics and Technology (FizTech) and the Institute for Problems in Mechanics, Sasha was affiliated mainly with three research institutions in three different countries: the Karpov Institute of Physical Chemistry in Moscow, Russia, the Technion in Haifa, Israel, and Northwestern University in Evanston, USA. During the last 8 years of his life Sasha was professor of applied mathematics at Northwestern.

Sasha's excellent background in physics and mathematics allowed him to work in many different areas. These include Marangoni convection, moving contact lines, combustion fronts, self-organization of quantum dots, nano-structures in electrochemical systems, control of morphological instabilities in crystal growth, and many others. His main interest was in studying nonlinear dynamics and pattern formation in numerous physical problems, in which dynamics and patterns played a crucial role. Sasha had the talent of finding interesting problems to work on even in research areas that he never studied.

Sasha was a kind man and a loyal friend. He had a sunny disposition always seeing the bright side of life. If I had to single out one quality that distinguished Sasha from other people, I would note his desire to help everybody. This help ranged from helping a student with a research project (by far exceeding hours and efforts that most of us would offer) to helping dozens of friends find a job (in all three countries where Sasha used to live), to offering money to somebody in need (regardless of whether Sasha had this money or would have to borrow it himself). He was generous and altruistic both in everyday life and in his research.

I would like to cite a colleague of ours who said: "I was thinking at the funeral that you often hear these great things said about the person who left us, but this time every word 
was absolutely true". Sasha will be remembered by all who knew him.

On behalf of Sasha's colleagues and friends, Vladimir Volpert 